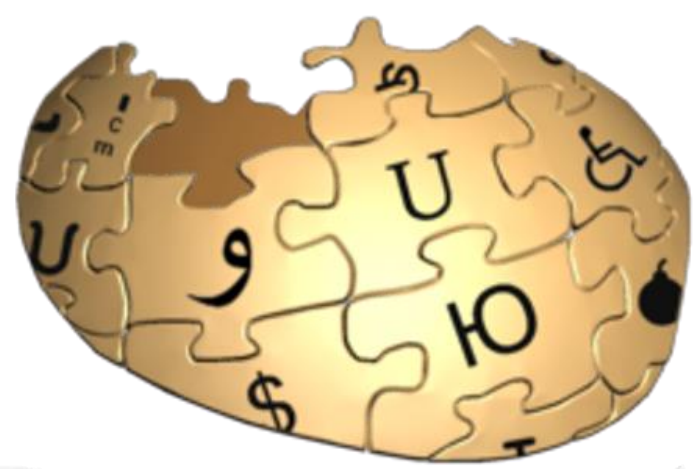

\title{
Dialetos/Línguas do Brasil na Desciclopédia
}

\author{
Dialects/Languages of Brazil on the Uncyclopedia
}

\author{
Ana Cláudia Fernandes Ferreira ${ }^{1}$ \\ Joelma Pereira de Faria ${ }^{2}$
}

\section{Resumo:}

Este trabalho objetiva analisar os modos como alguns dialetos/línguas do Brasil são significados em três artigos da Desciclopédia: Paulistanês, Mineirês e Disschionario Aurélo da Língua Carioca. De uma perspectiva discursiva da história das ideias linguísticas no Brasil em articulação com a semântica da enunciação e com estudos sobre saber urbano e linguagem, propomos desenvolver nossas análises buscando responder a questões como: $O$ que se constrói como coisas- $a$ saber (Pêcheux, 1983) sobre dialetos e línguas nesses artigos? Que memórias da história contraditória da gramatização brasileira do português (Orlandi e Guimarães, 2001) vão sendo aí mobilizadas? De que maneiras essas memórias se mantêm no espaço do dizível que advêm de outras enciclopédias, bem como da gramática e da linguística? Em que medida a Desciclopédia promove uma abertura para a constituição de outros espaços de dizer sobre os dialetos/línguas do Brasil? Como os nomes, termos, títulos, definições, classificações e descrições presentes nesses artigos da Desciclopédia, em que o humor é parte constitutiva e fundamental, produzem efeitos sobre os modos de significação dos dialetos e línguas aí envolvidos?

Palavras-chave: Dialetos/Línguas do Brasil. Termos. Nomes. Definições. Descrições. Desciclopédia.

\begin{abstract}
:
This work aims to analyze how some dialects/languages from Brazil are meant in three articles of Uncyclopedia: Paulistanês, Mineirês e Disschionario Aurélo da Língua Carioca. Based on a discursive perspective of the History of Linguistic Ideas in Brazil, in articulation with Enunciative Semantics and with studies based upon Urban Knowledge and Language, we propose to develop our analyses in order to answer such questions as: What is built as things-to-know (Pêcheux, 1983) about dialects and languages in these articles? What memories of the contradictory history of Brazilian gramatization of Portuguese (Orlandi \& Guimarães, 2001) are mobilized in there? How are these memories kept in the saying space that comes from other encyclopedias, as well as the grammar and linguistics ones? How the Uncyclopedia promotes an opening to the constitution of other spaces of saying about the dialects/languages of Brazil? How the names, terms, titles, definitions, classifications and descriptions on these articles of Uncyclopedia, in which humor is fundamental and constitutive part, produce effects upon the meaning ways of dialects and languages in there involved?
\end{abstract}

Keywords: Dialects/Languages of Brazil. Terms. Names. Definitions. Descriptions. Uncyclopedia.

\footnotetext{
${ }^{1}$ Professora do Programa de Pós-Graduação em Ciências da Linguagem - PPGCL da Universidade do Vale do Sapucaí - Univás, Pouso Alegre - MG. E-mail: anaclau@ymail.com. Endereço: Avenida Pref. Tuany Toledo, 470. 37550-000 - Pouso Alegre - MG, Brasil.

${ }^{2}$ Professora do Programa de Pós-Graduação em Ciências da Linguagem - PPGCL da Universidade do Vale do Sapucaí - Univás, Pouso Alegre - MG. E-mail: joelma.faria@uol.com.br. Endereço: Avenida Pref. Tuany Toledo, 470. 37550-000 - Pouso Alegre - MG, Brasil.
} 


\section{Introdução}

Em nosso dia-a-dia, quando conversamos sobre outras cidades, outros estados ou outras regiões do Brasil que não a nossa cidade, nosso estado e nossa região, a questão das diferenças linguísticas é, muitas vezes, um dos primeiros e preferidos temas da conversa. Esse tema das diferenças linguísticas no espaço brasileiro é parte do nosso saber linguístico cotidiano, um saber que suscita interesse e curiosidade, e que é movido por afetos, pelo humor, por conflitos, por disputas, etc. Um saber linguístico que não é uno ou unívoco, mas que também não é aleatório. Ele está relacionado a saberes já construídos, legitimados ou não, teorizados ou deixados de lado pelas teorias. Saberes que circulam e que significam, para aquém e para além do espaço da ciência. A Desciclopédia, ao lado de outros artefatos tecnológicos produzidos no início deste século XXI na internet, é um observatório interessante para a compreensão desse saber. ${ }^{3}$

De uma perspectiva discursiva da história das ideias linguísticas, nosso trabalho propõe analisar artigos da Desciclopédia dedicados à descrição de dialetos/línguas do Brasil, olhando para os modos pelos quais esses dialetos/línguas são significados enquanto nomes, em relação a termos e a partir de definições, classificações genéticas, recortes regionais e descrições. Essa perspectiva da história das ideias linguísticas se constitui por uma filiação à análise de discurso, a partir dos trabalhos de M. Pêcheux e de E. Orlandi, em articulação com a semântica da enunciação, na linha dos estudos de E. Guimarães ${ }^{4}$. Dessa perspectiva, a compreensão sobre a produção e a circulação de conhecimento sobre a linguagem em diferentes artefatos tecnológicos é fundamental ${ }^{5}$.

\footnotetext{
${ }^{3}$ De acordo com a Wikipédia, a Uncyclopedia foi criada em janeiro de 2005 e a Desciclopédia foi criada em agosto do mesmo ano.

${ }^{4}$ Notadamente, pela mobilização dos conceitos de nomeação, designação e referência, ao lado dos conceitos de reescrituração e articulação, formulados pelo autor em Guimarães (2002, 2004). Segundo o autor, "A nomeação é o funcionamento semântico pelo qual algo recebe um nome (...). A designação é o que se poderia chamar de significação de um nome, mas não enquanto algo abstrato. Seria a significação enquanto algo próprio das relações de linguagem, mas enquanto uma relação linguística (simbólica) remetida ao real, exposta ao real, ou seja, enquanto uma relação tomada na história. (...). A referência será vista como a particularização de algo na e pela enunciação" (2002, p. 9). Quanto aos procedimentos de articulação eles "dizem respeito às relações próprias das contiguidades locais. De como o funcionamento de certas formas afeta outras que elas não redizem" (Guimarães, 2004: p. 18). E a reescrituração, conforme o autor "é o procedimento pelo qual a enunciação de um texto rediz insistentemente o que já foi dito, fazendo interpretar uma forma como diferente de si" (Guimarães, 2004, p. 17). E ao redizer o que já foi dito, produz-se uma deriva do sentido (Guimarães, 2002).

${ }^{5}$ Em relação a isso, destacamos os estudos de S. Auroux $(1992,1998)$ sobre as revoluções tecnológicas da escrita, da gramatização das línguas do mundo e da mecanização da linguagem, bem como o trabalho de A. Ferreira (2015) sobre o papel e o poder fundador da linguagem na relação com o conhecimento e a tecnologia.
} 
Ao lado disso as relações entre saber urbano e linguagem também têm sido fundamentais para o desenvolvimento dessas pesquisas ${ }^{6}$.

Os artigos escolhidos para a análise são três: 1) Paulistanês; 2) Minerês; e 3) Disschionario Aurélo da Língua Carioca. Com essa análise, refletimos sobre diversos modos pelos quais a textualidade desses artigos da Desciclopédia, em sua especificidade, (se) constrói (em) uma memória de sentidos de conhecimentos sobre as línguas no espaço brasileiro, numa relação tensa e contraditória entre dialeto e língua, entre língua portuguesa e língua brasileira, e entre língua imaginária e língua fluida (Orlandi, 2009).

A partir da perspectiva em que nos colocamos, buscamos respostas para questões como: O que se constrói como coisas-a-saber (Pêcheux, 1983) sobre dialetos e línguas nesses artigos? Que memórias da história contraditória da gramatização brasileira do português (Orlandi e Guimarães, 2001) vão sendo aí mobilizadas? De que maneiras essas memórias se mantêm no espaço do dizível que advém de outras enciclopédias, bem como da gramática e da linguística? Em que medida a Desciclopédia promove uma abertura para a constituição de outros espaços de dizer sobre os dialetos/línguas do Brasil? Como os nomes, termos, títulos, definições, classificações e descrições presentes nesses artigos da Desciclopédia, em que o humor é parte constitutiva e fundamental, produzem efeitos sobre os modos de significação dos dialetos e línguas aí envolvidos?

\section{As enciclopédias digitais e suas especificidades}

Atualmente, uma série de trabalhos nas áreas de análise de discurso, saber urbano e linguagem e história das ideias linguísticas tem se dedicado a estudar enciclopédias digitais. Podemos lembrar aqui o trabalho de L. Scotta (2008), que concebe a passagem das enciclopédias tradicionais como um círculo que se fecha para a Wikipédia como uma rede que se abre. Lembramos também G. Henge (2009), que discute a historicidade da cibercultura e do hipertexto, e investiga como se se constitui aí um modo de escrita, configurado como autoria colaborativa, que relaciona os sujeitos e os saberes em redes discursivas dos artigos da Wikipédia. Lembramos ainda o percurso analítico de J. H. Nunes (2012a) sobre o aparecimento do discurso

\footnotetext{
${ }^{6}$ Destacamos aqui a área de Saber urbano e linguagem do Laboratório de Estudos Urbanos da Unicamp, que tem contribuído para o desenvolvimento de diversas pesquisas a respeito da cidade, das novas tecnologias e da internet por meio de uma abordagem discursiva, relacionando o sujeito, a linguagem e a história.
} 
enciclopédico no Brasil do século XX até o início do século XXI, e J. H. Nunes (2012b) que apresenta o projeto de uma Enciclopédia Discursiva da Cidade.

Ao lado disso, gostaríamos de destacar a observação de J. H. Nunes (2014), de que a Wikipédia, ao se propor como uma "enciclopédia universal e multilíngue" e como "A enciclopédia livre que todos podem editar", se insere no discurso da globalização, significando em seus verbetes o global e o local. Destacamos também as considerações de A. Ferreira (2012) sobre a Enciclopédia Abril, a Wikipédia e a Desciclopédia, que apontam para a passagem do especialista, com sua legitimidade científica assegurada, para o todos, que tem essa legitimidade questionada, e para o qualquer um, que fica isento desse tipo de legitimidade. ${ }^{7}$ Destacamos ainda, a reflexão de A. Ferreira (2013) de que uma das diferenças entre artigos sobre diferentes cidades na Wikipédia e na Desciclopédia é que, nesta última, as cidades são significadas, logo no início da página dos artigos, por seus dialetos/línguas regionais, que ora são significados como dialetos, ora como línguas. Junto a isso, outro ponto salientado é que a Desciclopédia, enquanto uma paródia da Wikipédia, não produz apenas preconceitos, mas também críticas, contestações e outras possibilidades de sentido para o sujeito, a linguagem, o mundo e o saber. Isso porque preconceitos também estão presentes em outras enciclopédias, mas de outros modos, menos visíveis e, por isso mesmo, mais eficazes. ${ }^{8}$

Situando nosso trabalho junto a este conjunto de reflexões, buscamos observar como são produzidos saberes sobre alguns dialetos/línguas do Brasil, nomeados pelo qualquer um da Desciclopédia como paulistanês, mineirês ${ }^{9}$ e carioquês, investigando suas especificidades, e examinando de que maneira eles se constituem numa relação contraditória com os saberes linguísticos legitimados por outras enciclopédias, pela gramática e pela linguística. Desenvolvemos essa reflexão tendo em vista os modos de significação dos nomes dos dialetos/línguas, dos termos língua e dialeto, dos títulos dos artigos, bem como das definições, classificações genéticas, recortes regionais e descrições elaborados nesses artigos.

\section{Títulos, nomes e termos...}

\footnotetext{
${ }^{7}$ A. Ferreira (2012) discute acerca dessa passagem observando que, enquanto a Enciclopédia Abril conta "com a colaboração de quase uma centena de especialistas altamente categorizados", a Wikipédia é definida como "a enciclopédia livre que todos podem editar", e a Desciclopédia é definida como "a enciclopédia livre de conteúdo e que qualquer um pode editar".

${ }^{8}$ Entendemos a paródia em seu sentido amplo, como ao lado de outro, tal como propôs E. Orlandi (2002).

${ }^{9}$ Há uma alternância, no artigo, entre as formas minerês e mineirês.
} 
Os artigos da Desciclopédia intitulados de Paulistanês, Minerês e Disschionario Aurélo da Língua Carioca tratam dos dialetos/línguas nomeados, no corpo dos artigos, de paulistanês, minerês e carioquês.

De início, vale notar que o título do artigo Disschionario Aurélo da Língua Carioca era Carioquês em suas primeiras versões. Após a mudança de título, o endereço da página do artigo permaneceu com a palavra carioquês do título original: http://desciclopedia.org/wiki/Carioquês. A substituição do título produziu uma especificação interessante para o artigo, que é ressignificado como um dicionário, numa paródia com o dicionário Aurélio. Por meio dessa paródia, o carioquês é significado não simplesmente como dialeto, mas como língua: a língua carioca. Antes da substituição do título do artigo, os sentidos de carioquês talvez estivessem mais facilmente relacionados ao termo dialeto do que ao termo língua. Depois da substituição, essa relação entre dialeto e língua fica mais complexa e tensionada.

Outro ponto a observar é o fato de um artigo da Desciclopédia sobre um dialeto/língua se apresentar como um dicionário e o efeito que isso produz na relação entre os saberes em geral e entre os saberes linguísticos em particular. O artigo, intitulado como um dicionário, significa como uma paródia de um instrumento linguístico específico no interior de outra paródia, a de um instrumento enciclopédico. Ou seja, o artigo significa como uma paródia de uma descrição de um saber linguístico sobre um dialeto/língua no interior de uma paródia de uma descrição de um saber a respeito das coisas do mundo. Já os artigos Paulistanês e Minerês, por não serem definidos como gramáticas, dicionários ou como outro tipo de instrumento linguístico significam como uma paródia de uma descrição de um saber linguístico sobre um dialeto/língua enquanto uma paródia de uma descrição a respeito das coisas do mundo.

Também é interessante indicar algumas relações de sentido entre os nomes paulistanês, minerês e carioquês e os nomes paulistano, mineiro e carioca. Estes últimos designam tanto os sujeitos que são naturais da cidade de São Paulo, do Estado de Minas Gerais e da cidade do Rio de Janeiro, quanto os nomes dos dialetos falados por esses sujeitos nessas regiões do Brasil. Esse saber, que está presente de uma maneira singular na Desciclopédia, é proveniente da circulação de alguns conhecimentos científicos da dialetologia e da linguística que se popularizaram em nossa sociedade, na história.

A propósito disso, vale notar que a terminação - $\hat{e}$, de paulistanês, minerês e carioquês, desfaz ambiguidade entre os sujeitos paulistano, mineiro e carioca e os 
dialetos/línguas paulistano, mineiro e carioca. Isso não significa, é claro, que, na Desciclopédia, os sentidos sobre esses dialetos/línguas deixem de ser produzidos, entre outras coisas, pela relação com seu(s) sujeito(s) falantes ${ }^{10}$.

A terminação -ês funciona como marca indicativa de que essas palavras são nomes de dialetos/línguas, ao modo de português, francês, japonês, etc. Os textos desses artigos lançam mão de um saber linguístico que mobiliza um funcionamento da flexão pela produtividade da terminação - $̂$ s para construir/inventar o nome de um dialeto ou língua ${ }^{11}$.

Se nos mantivermos apenas na análise dos títulos dos artigos e dos nomes dos dialetos/línguas, poderíamos deduzir que o paulistanês e o minerês podem significar como dialetos e que o carioquês significa como língua. No entanto, analisando outros espaços dos textos desses artigos da Desciclopédia, vislumbramos o funcionamento de uma tensão desestabilizadora dos termos dialeto e língua em relação a esses nomes.

A propósito dessa questão, cabe salientar que a tensão entre língua e dialeto é parte constitutiva da história das línguas e do conhecimento sobre elas, e tem um lugar importante na história brasileira, notadamente com as polêmicas em torno do nome da língua nacional, surgidas no século XIX, "resolvidas” no início do século XX, e ligadas à gramatização brasileira do português, iniciada no final do século XIX. A constituição da língua nacional do Brasil está relacionada inextricavelmente a esta gramatização, produzida no espaço contraditório entre o específico brasileiro e o modelo português.

Vejamos isso mais de perto nos itens a seguir, que analisam as definições, as classificações genéticas, os recortes regionais e algumas descrições de cada dialeto/língua presente nos artigos.

\section{Definições}

\footnotetext{
${ }^{10}$ Ressaltamos que, além das diferentes maneiras de recortar o espaço desses dialetos/línguas regionais nos artigos que analisamos, também há diferentes relações entre os dialetos/línguas e os sujeitos. Não nos detemos neste ponto em nosso trabalho, mas pensamos ser importante mencioná-lo e retomar, a título de ilustração, um aspecto destacado por A. Ferreira (2013) a esse respeito em suas comparações que relacionam as classificações genéticas e outros itens dos artigos sobre o Paulistanês e o Mineirês. Uma dessas diferenças no modo de recortar o espaço dos dialetos/línguas é apontada na análise do item do artigo sobre o Paulistanês intitulado de História, em que a origem do paulistanês é remetida a diferentes sujeitos: portugueses, índios, italianos, turcos, japoneses, ingleses, coreanos e árabes. Nessa história, que relaciona o dialeto/língua com diferentes sujeitos, há um destaque para os italianos - 'os italiano pricipalmentz' - e uma conclusão que aponta para uma impossibilidade de chegar à origem para esse dialeto/língua - 'Ninguéim sabe quem é o pai do paulistanêis agora, meu'.

${ }^{11} \mathrm{E}$ isso, vale salientar, independentemente de o(s) sujeito(s) autores dos artigos saberem ou não sobre o que é flexão ou terminação e independentemente de terem ou não sido inventados, de fato, pelos sujeitos autores-editores dos artigos.
} 
As definições e outras partes que compõem o corpo do texto de cada artigo apresentam diferentes sentidos para a tensão dialeto/língua. Da perspectiva deste trabalho, não interessa fazer uma análise exaustiva que "explicaria de uma vez por todas" as contradições que jogam com essa tensão ou que as "resolveria". Isso porque, para nós, a contradição é constitutiva da constituição do conhecimento. Não há explicação ou resolução que elimine as contradições produzidas pelo conhecimento, seja ele qual for. Desse modo, pretendemos apenas dar alguma visibilidade a essas contradições.

Vejamos, então, um pouco das formas que essas contradições tomam no espaço singular da Desciclopédia, considerando as seguintes definições:

"Paulistanês é a língua oficial de paulista. Também é falada no resto do Brasil, na América, em Marte e no resto do universo." (itálicos nossos) http://desciclopedia.org/wiki/Paulistanês

"O Mineirês (Mneres) é um dialeto do Português, falado em Minas Gerais e no Estado do Triângulo uai (mas não diga isso pra qualquer triangulino, porque muitos não gostam muito de outros "países")." (itálicos nossos)

http://desciclopedia.org/wiki/Minerês

"O Carioquês (Kariokêiş) é um dialeto do Português, falado nos Estados do Rio de Janeiro, Espírito Santo e nos estúdios da Globo." (itálicos nossos) http://desciclopedia.org/wiki/Carioquês

Podemos observar, nestas definições, que o mineirês e o carioquês são designados como dialetos e o paulistanês é designado não apenas pelo termo língua, mas como "língua oficial de paulista". Entretanto, cabe lembrar que, embora a definição apresentada para o carioquês o designe como dialeto, no título do artigo, Disschionario Aurélo da Língua Carioca, o carioquês é reescrito como língua e, portanto, designado como língua.

Essa e outras "inconsistências" constroem modos específicos de tensão e contradição nos discursos da Desciclopédia e se devem tanto pelo fato de que vários sujeitos autores colaboram como editores dos artigos da Desciclopédia e se filiam a discursividades diferentes, quanto pelo fato de que a consistência, a clareza, a coesão etc., não são um pré-requisito para a produção do humor, da paródia, do nonsense nesse espaço de produção de saber. 
Os sujeitos que escrevem textos na Desciclopédia não são apenas autores, mas também editores. E, como o conjunto dos sujeitos autores-editores significados pelo qualquer um da Desciclopédia pode ser contraditório, a condensação dos textos desses diferentes sujeitos em um só artigo, com suas diferentes filiações de sentidos, acaba por ressignificar os termos dialeto e língua, os quais passam a funcionar sob uma espécie de efeito de sinonímia. $\mathrm{O}$ humor que resulta desse efeito de sinonímia denuncia o absurdo que poderia ser, do ponto de vista da ciência, a possibilidade de existência de um dialeto que é ao mesmo tempo uma língua e/ou o de uma língua que é ao mesmo tempo um dialeto, mas, ao denunciá-lo, dá a essa possibilidade uma existência.

Também é interessante observar como todas as três definições contém um complemento: falado em... Voltaremos a essa questão um pouco mais adiante, em nossas análises sobre os recortes regionais. Antes disso, analisaremos a relação dialeto/língua nas paródias das classificações genéticas.

\section{Classificações genéticas: nomes de línguas oficializados, teorizados e inventados}

Outro modo de definição e significação dos dialetos/línguas presente nos três artigos é uma paródia das classificações genéticas, apresentadas como um item no interior dos quadros a seguir, que retiramos de cada artigo:

\begin{tabular}{|l|l|}
\hline \multicolumn{2}{|c|}{ Paulistanês } \\
\hline Paulistanês & $\begin{array}{l}\text { "Aê mano, paulistanês, } \\
\text { porra!" }\end{array}$ \\
\hline Falado em: & Grande São Paulo, meu \\
\hline $\begin{array}{l}\text { Total de } \\
\text { falantes: }\end{array}$ & $\begin{array}{l}40 \text { milhões, meu (Paulistas, } \\
\text { São Paulo,2003) }\end{array}$ \\
\hline $\begin{array}{l}\text { Classificação } \\
\text { genética: }\end{array}$ & $\begin{array}{l}\text { Latim } \\
\text { Proto-ltálico } \\
\text { Português Galáctico } \\
\text { Português } \\
\text { Brasileiro }\end{array}$ \\
\hline SIL: & Paulistanês \\
\hline
\end{tabular}

Fonte: Desciclopédia. Paulistanês http://desciclopedia.org/wiki/Paulista nês

\begin{tabular}{|l|l|}
\hline \multicolumn{2}{|c|}{ Minerês } \\
\hline Minerês & "Mneres" \\
\hline Falado em: & Minas Gerais \\
\hline Total de falantes: & $\begin{array}{l}\text { obviamente a população } \\
\text { mnerinha }\end{array}$ \\
\hline $\begin{array}{l}\text { Classificação } \\
\text { genética: }\end{array}$ & $\begin{array}{l}\text { Latim } \\
\text { Proto-ltálico } \\
\text { Português Galáctico } \\
\text { Português } \\
\text { Brasileiro }\end{array}$ \\
\hline SIL: & Mineirês \\
\hline & MNR \\
\hline
\end{tabular}

Fonte: Desciclopédia. Minerês http://desciclopedia.org/wiki/Minerês

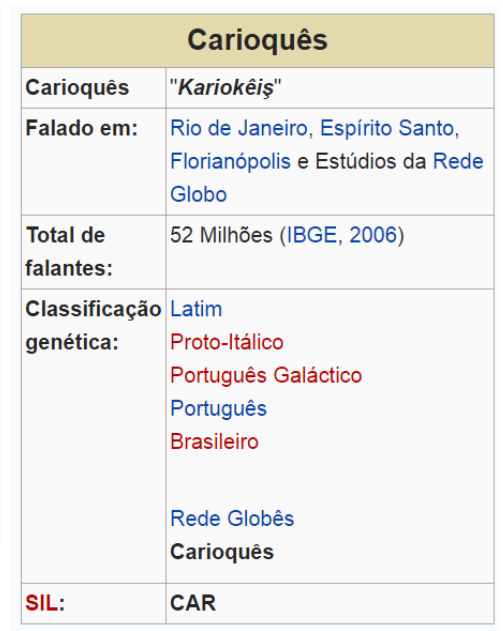

Fonte: Desciclopédia. Disschionario Aurélo da Língua Carioca http://desciclopedia.org/wiki/Carioqu $\underline{\underline{\hat{e}}}$

Podemos observar, aqui, pelos itens da classificação genética presentes nos quadros, que tanto o paulistanês, como o mineirês e o carioquês comparecem em uma ramificação, ao lado de outras línguas, como nomes de línguas. E, como tais, são 
significados ao lado de nomes de línguas oficializados (latim e português), nomes de línguas teorizados (proto-itálico, brasileiro) e nomes de línguas inventados (português galáctico, rede globês), funcionando, juntamente com estes últimos, enquanto nomes de línguas inventados.

Podemos dizer que, enquanto um nome oficializado deve sua existência à construção e legitimação de um Estado e/ou nação ${ }^{12}$, um nome teorizado deve sua existência à construção e legitimação por uma teoria do campo do conhecimento, e um nome inventado deve sua existência a outro tipo de construção e legitimação, que funciona no espaço do humor ${ }^{13}$.

Um dos efeitos da paródia é que esses diferentes nomes, oficializados, teorizados e inventados, que designam línguas colocadas em relação no interior dessas classificações genéticas, comparecem indistintos. Em outras palavras, é como se não houvesse uma distinção entre esses nomes que significam como oficializados, teorizados e inventados. No entanto, isso se dá de tal modo que, pelo próprio jogo parodístico, tal efeito de indistinção não apaga a distinção, mas joga com ela, debocha dela, a mobiliza e a desestabiliza, desestabilizando os diferentes sentidos sobre as línguas e seus nomes.

Nesse movimento de sentidos, o latim é apresentado como origem dessas línguas, ao mesmo tempo em que elas passam pelo português e depois pelo brasileiro. Temos aí, com a metáfora da classificação genética, em que o latim é colocado como origem, a apropriação de um discurso científico dominante sobre a história das línguas em geral, do campo da linguística histórico-comparativa. $\mathrm{O}$ fato de encontrarmos essa metáfora em um artigo da Desciclopédia nos mostra que, embora esse discurso científico do latim como

\footnotetext{
${ }^{12}$ No Brasil, atualmente, há duas línguas oficiais: a língua portuguesa e a língua brasileira de sinais. Mas também é importante salientar que, recentemente, diversos municípios reconheceram outras línguas como oficiais, como, por exemplo, o pomerano, de Pomerode, e o nheengatu, o tukano e o baniwa, de São Gabriel da Cachoeira. Desse modo, podemos dizer que essas línguas passaram a ter outro estatuto pela oficialização, ainda que regionalmente.

${ }^{13}$ Compreendemos essa distinção em uma articulação com a distinção proposta por E. Orlandi (1983) entre discurso lúdico, polêmico e autoritário. Com essa articulação observamos essas distinções, não isoladamente, mas em sua relação contraditória, na qual os nomes inventados tendem para o lúdico, os nomes teorizados tendem para o polêmico e os nomes oficializados tendem para o autoritário. Ao lado disso, podemos compreender como, a partir do espaço do espaço do humor, a partir do espaço do teórico e a partir do espaço do oficial, esses nomes significam diferentemente. E ainda: se compreendemos, por essa articulação, que todos os nomes são, a princípio, inventados, devemos compreender também que eles têm estatuto diferentes no espaço do humor, no espaço do científico e no espaço do oficial. Consideramos, para o presente trabalho, os nomes inventados num sentido mais restrito, enquanto nomes inventados no espaço do humor. Nesse sentido, os nomes inventados, teorizados e oficializados podem ser questionados e polemizados no espaço do teórico e também no espaço do humor, de maneira diferentes, mas dificilmente o são no espaço do oficial. Ou seja, no espaço do oficial, o que se admite é apenas o oficial.
} 
língua mãe do português (e de outras línguas) seja muitas vezes questionado no campo dos estudos da linguagem, pelos apagamentos que produziu sobre as relações de contato/confronto entre as línguas, ele continua dominando e produzindo seus efeitos, circulando amplamente para além do domínio científico.

Por outro lado, temos aí a apropriação de uma distinção entre português e brasileiro na qual a palavra brasileiro não funciona como determinante da palavra dialeto, mas significa como nome de uma língua. Cabe notar que a diferença das cores dos nomes das línguas, presentes nos quadros das classificações genéticas, entre azuis (latim, português e rede globês) e vermelhas (proto-itálico, português galáctico e brasileiro), reside no fato de que os nomes em azul contêm links para outros artigos existentes e os nomes em vermelho contêm links para artigos que ainda não existem (ou existiram e foram apagados). No caso do nome brasileiro, que está em vermelho, o link direciona para uma página da Desciclopédia que diz:

\section{"Criando Língua brasileira}

Você clicou em um link para um artigo que ainda não existe. Para criá-lo, escreva o seu conteúdo na caixa abaixo, mas se você chegou aqui por engano clique no botão voltar (ou back) do seu navegador." (grifos nossos) http://desciclopedia.org/index.php?title=Língua_brasileira\&action=edit\&redl ink=1

Dessa maneira, brasileiro e língua brasileira significam como sinônimos, enquanto uma língua, e como nomes de uma língua. Os nomes dessa língua existem no espaço da Desciclopédia, e mesmo um link para um artigo sobre ela já existe nesse espaço, apesar de o artigo que trata dela ainda não existir.

A esse respeito, é importante salientar que a possibilidade da enunciação de brasileiro como língua e como nome de língua, ao lado de língua brasileira está ligada, incontornavelmente, à história das ideias linguísticas e das línguas no/do Brasil. Nessa história, podemos encontrar um grande número de estudos, que remontam ao início do século XIX, para os quais a distinção entre língua portuguesa e língua brasileira é uma questão fundamental.

Em relação a isso, lembramos, a partir de E. Orlandi e E. Guimarães (2001), que a questão do nome da língua do Brasil é oficialmente formulada no Brasil poucos anos após a independência, em 1826, com a proposta de um deputado ao parlamento de que os diplomas dos médicos fossem redigidos em linguagem brasileira. Já no ano seguinte, 
em 1827, após longas discussões que se seguiram a esta proposta, foi estabelecida uma lei determinando que os professores ensinassem a ler e a escrever utilizando a gramática da língua nacional. De acordo com os autores, a formulação desta lei evitou nomear oficialmente a língua, seja como língua portuguesa, seja como língua brasileira, tendo assim a questão contornada por meio da nomeação língua nacional.

Também é importante lembrar que, a partir da segunda metade do século XIX, a questão do nome da língua do Brasil (questão que se coloca já sob o efeito de unidade de uma língua única no país) se torna objeto de inúmeros estudos científicos. São estudos produzidos a partir de diferentes perspectivas e posições sobre a língua e sobre o nome da língua. Estes estudos não pararam de ser realizados após a decisão oficial da comissão que, em atendimento ao estabelecido pela constituição de 1946, decidiu que "o nome do idioma falado no Brasil é Língua Portuguesa" ${ }^{14}$. Esses estudos atravessaram o século XX e chegaram ao século XXI. ${ }^{15}$

Esta distinção continua sendo discutida, sob várias perspectivas, no campo do conhecimento científico. Podemos dizer que a possibilidade de esta distinção comparecer em um artigo da Desciclopédia se deve a essa história. Mesmo que o Estado e as teorias dominantes da ciência não considerem a língua brasileira, seu nome continua circulando e produzindo efeitos para além do domínio científico.

Essa possibilidade se dá, ainda que o nome da língua oficial do Brasil seja língua portuguesa. Podemos dizer, sem dúvida, que há um efeito de impossibilidade (como se fosse impossível) para o especialista de uma enciclopédia tradicional, para muitos cientistas da linguagem, e talvez também para o todos da Wikipédia de enunciar sobre a língua brasileira. Isso mostra o forte papel que tem o Estado, para o qual a língua oficial é o português, na produção da ciência. Entretanto, a língua brasileira é possível de ser enunciada pelo qualquer um da Desciclopédia, que não possui compromisso com o discurso oficial e não precisa se filiar a um discurso científico dominante e nem a um discurso científico apenas, mas a vários discursos, contraditoriamente.

Assim, de um lado, a possibilidade da enunciação da língua brasileira nesses artigos da Desciclopédia se funda sob uma série de discursividades que circulam sobre a própria especificidade das relações de línguas no espaço brasileiro. Discursividades

\footnotetext{
${ }^{14}$ Uma análise da decisão oficial sobre o nome da língua pode ser apreciada em E. Guimarães (2000).

${ }^{15}$ A respeito do início do século XX, vale lembrar, por exemplo, as obras de João Ribeiro (1933), Edgard Sanches (1940), Gladstone Chaves de Melo (1946, 1948), Herbert P. Fortes (1957a, 1957b). A respeito do final do século XX e início do século XXI, vale lembrar, por exemplo, as obras de E. Orlandi (1985, 2009, 2014), E. Orlandi e T. Souza (1988), E. Guimarães (2000) e L. F. Dias (1996, 2013, 2015).
} 
estas em que perpassam alguns discursos científicos, dos séculos passados e atuais, bem como discursos do senso comum. Discursividades oriundas do entrecruzamento de saberes científicos, saberes científicos sustentados oficialmente e também saberes outros, cotidianos, produzidos pelo funcionamento do ordinário do sentido (Pêcheux, 1983). É nesse espaço que a Desciclopédia pode parodiar, transitando entre o oficializado, o teorizado e o inventado.

De outro lado, os artigos também se apropriam de uma teoria da evolução das línguas que reproduz um saber científico tradicional e vulgarizado. Um saber no qual a evolução de uma língua é tomada, muitas vezes, de maneira linear, sem considerar as relações de contato/confronto entre as línguas na história. A partir dessa história tradicional da evolução das línguas, várias línguas ficam de fora no caminho linear na classificação genética da Desciclopédia. Aqui, embora brasileiro seja considerado como uma língua, a relação de origem é estabelecida apenas com o português e não com as línguas indígenas, línguas africanas e línguas de colonizadores e viajantes com as quais o português teve contato no Brasil. Há, assim, um apagamento dessas línguas na classificação apresentada.

Nessa relação entre diferentes saberes, a invenção do paulistanês, do mineirês e do carioquês nos artigos da Desciclopédia que analisamos construiu outro espaço de significação para os dialetos/línguas regionais do Brasil em relação ao português e ao brasileiro.

\section{Recortes regionais}

Avançando nossa reflexão, é interessante notar de que maneiras o paulistês, o mineirês e o carioquês significam por meio de recortes regionais diferentes. Essas diferenças podem ser notadas confrontando os recortes construídos pelas delimitações de falado em nos itens dos quadros apresentados no item anterior com as delimitações apresentadas no item das definições.

Observando as delimitações dos quadros do item anterior, no caso do paulistanês, o recorte é 'Grande São Paulo, meu'. O paulistanês significa como um dialeto/língua de todos os sujeitos falantes da região metropolitana de São Paulo e não apenas da cidade de São Paulo. No caso do mineirês, o recorte é 'Minas Gerais', coincidindo com o espaço delimitado pelo estado de Minas Gerais, não sendo falado somente em uma cidade, como Belo Horizonte, mas em todas as cidades do estado. No caso do carioquês, o recorte é 'Rio de Janeiro, Espírito Santo e Estúdios da Rede 
Globo', ultrapassando os limites entre cidades e as divisas entre estados, e recobrindo também o estado do Espírito Santo.

Confrontando estes recortes com aqueles apresentados nas definições, podemos notar que a definição do paulistanês tem o recorte regional da 'Grande São Paulo, meu' ampliado, sendo falado 'também' 'no resto do Brasil, na América, em Marte e no resto do universo'. Em relação à definição do mineirês, há uma divisão do estado de Minas Gerais, na qual ele é falado em 'Minas Gerais e no Estado do Triângulo', também produzindo um recorte diferente daquele da classificação genética. E em relação ao carioquês, o recorte regional é igual ao da classificação genética.

Esses recortes não são sempre aleatórios ou absurdos, mas jogam com o absurdo do espaço, como o do paulistanês, falado em 'Marte e no resto do universo'. Ou com o absurdo da história e da geografia política, como no recorte para o minerês que apresenta uma divisão do Estado de Minas Gerais não correspondente à divisão geopolítica atual, mas que é significativa na história brasileira. Isso porque a região do Triângulo Mineiro já pertenceu à antiga Província de São Paulo e porque, atualmente, existem propostas de separação desta região do Estado de Minas Gerais para a criação de um Estado do Triângulo. No caso do carioquês, os recortes regionais jogam com o absurdo da mídia como o espaço de um dialeto/língua, pelo rede globês. E também parodiam estudos realizados no domínio da dialetologia. Há, de certo modo, semelhanças com a divisão elaborada por Antenor Nascentes (1953), para 'A posição do linguajar carioca no conjunto do falar brasileiro' (p. 18-26). De acordo com Nascentes, o fluminense é um subfalar do conjunto do falar brasileiro que recobre o Rio de Janeiro, o Espírito Santo e parte de Minas Gerais, e o linguajar carioca é uma variedade do subfalar fluminense ${ }^{16}$. No caso da divisão da Desciclopédia, o carioquês, ou a língua carioca, é um dialeto/língua de toda essa região.

\section{Descrições}

Um último aspecto dos artigos da Desciclopédia sobre o paulistanês, o mineirês e o carioquês, que tomamos para as análises deste trabalho, é o das descrições.

\footnotetext{
${ }^{16}$ Vale observar que o título da primeira edição da obra de Nascentes, de 1922, é O linguajar carioca em 1922. O título da segunda edição, de 1953, que contém o mapa do falar brasileiro elabora pelo autor, ficou apenas $O$ linguajar carioca. Também é interessante notar que, na primeira edição, há uma indecisão sobre a existência ou não de um dialeto brasileiro, discutida no item $O$ dialecto brasileiro. Na segunda edição, isso fica decidido e o título passa a $O$ falar brasileiro.
} 
Há diversas formas de descrição em funcionamento nesses três artigos. De modo geral, nos textos, há uma apropriação de um modo de descrever próprio da escrita científica para produzir o humor. Esse humor parodístico se produz tanto pela descrição de objetos que dificilmente seriam objetos de estudo de um sujeito especialista, seja ele gramático ou linguista, ou então de objetos que dificilmente seriam descritos pelo especialista do modo como o são na Desciclopédia. A esse respeito, embora os artigos da Desciclopédia não sejam legitimados pelo científico, há, nela conhecimentos legítimos. E, ao lado disso, há uma legitimidade específica de saberes que funciona nesse espaço do humor. ${ }^{17}$ Ou seja, na Desciclopédia, a legitimidade é de outra ordem, que mistura, pelo humor, saberes linguísticos oriundos de gramáticas e da linguística com saberes linguísticos do nosso cotidiano.

No caso específico do humor da paródia, para que ele se produza, as descrições podem se basear em proposições, formulações, hipóteses e histórias que são absurdas ou então que vão de encontro com sentidos já estabelecidos, estabilizados e legitimados. O que não significa que textos científicos não possam também ser produzidos pelo absurdo e pelo não estabelecido, não estabilizado e não legitimado. Aliás, a história dos estudos da linguagem não seria sobre a linguagem se o absurdo não fizesse parte dela e a produção do saber não seria possível se ela permanecesse no que estaria já estabelecido, estabilizado e legitimado. No entanto, consideramos que a produção de um saber de modo geral e de um saber linguístico em particular só pode se dar enquanto humor parodístico se o saber aí produzido significar (n)uma relação de alteridade específica com um saber existente e, de tal modo, que faça rir.

Ao lado disso, ressaltamos que o qualquer um da Desciclopédia é um sujeito urbano escolarizado (Pfeiffer, 2000). No caso dos artigos que aqui estamos analisando, esse sujeito possui um conhecimento linguístico gramatical, a partir do qual se apropria para inventar e descrever, com humor, o paulistanês, o mineirês e o caipirês. Ao ocupar o lugar do qualquer um e, desse modo, de autor-editor desses artigos da Desciclopédia, o sujeito e a legitimidade do saber que ele produz adquirem outro estatuto, determinado pelo humor.

\footnotetext{
${ }^{17}$ A distinção entre gramática (normativa) e linguística (científica) tem uma validade e um interesse, ainda que com limitações. Mesmo que ambos os domínios possuam suas especificidades, de um lado, há descrições científicas em uma gramática normativa e, de outro, a linguística pode produzir normas por meio de suas descrições (podendo também acontecer de descrições linguísticas deslizarem para normas).
} 
Nos artigos que são objeto de nossa análise, há várias formas de apropriação de um texto descritivo científico gramatical ou linguístico. Tomamos aqui apenas quatro pequenos exemplos de descrição desse tipo de apropriação:

\section{Paulistanês}

"A pronúncia correta do paulistês deve seguir regras básicas de colocação. Tal como no Mandarim, entonações incorretas podem alterar o sentido da frase." $" 18$

Mineirês

$$
\begin{aligned}
& \text { "Vocabulário Elementar } \\
& \text { Pronomes } \\
& \text { "Eu" = Eu } \\
& \text { "Cê" = Tu } \\
& \text { "Eli" = Ele } \\
& \text { "Nóis" = Nós } \\
& \text { "Ceis" = Vós } \\
& \text { "Ês" = Ele" }
\end{aligned}
$$

Carioquês

“(...) uma característica do dialeto é a demora para concluir as palavras. Ao contrário de outros dialetos, que demoram devido à lerdeza de raciocínio de seus falantes (ver: mineirês e baianês), a demora no carioquês se deve ao fato de seus falantes puxarem absurdamente seus "S's", "R's", além de se utilizarem de diversas interjeições, tais como "aih", ou semifrases que nada acrescentam ao conteúdo da frase, como "coé"."

No exemplo sobre o paulistanês, há uma menção a regras de colocação de acento na pronúncia, que é relacionada a um problema de sentido proveniente da incorreção da entonação e a uma comparação com outra língua, o mandarim. Ou seja, a formulação faz uma paródia de uma prescrição gramatical. No entanto, se desconsideramos a comparação com o mandarim, podemos dizer que a prescrição do paulistanês poderia servir para qualquer dialeto/língua.

No exemplo sobre o mineirês, há uma relação de formas pronominais que são comparadas com formas equivalentes em português. Nessa comparação, as aspas marcam um distanciamento do sujeito autor em relação às formas do mineirês, significando as formas do português que aprendemos nas gramáticas, como as legitimadas. O efeito de evidência do $e u$, tu, ele, nós, vós, eles é aí eficaz, além de bastante ilustrativo para pensarmos o papel que teve a gramatização dessa série para o

\footnotetext{
${ }^{18}$ No artigo, há uma alternância entre paulistês e paulistanês, predominando a forma paulistanês.
} 
sujeito urbano escolarizado brasileiro: ele nem sempre consegue formulá-la diferentemente, ainda que ela não faça parte de sua realidade, nem na fala, nem na escrita, como frequentemente ocorre com o $t u$ e principalmente o vós. Essa série funciona como se fosse automática, principalmente quando a associamos aos exercícios de conjugação: Qual é a conjugação do verbo ser? Eu sou, Tu és, Ele é; Nós somos, Vós sois, Eles são. De outro lado, a série de pronomes descrita para o mineirês é, sem dúvida, mais consequente com o que conhecemos como dialeto mineiro, além de estar mais próxima da série de pronomes que funciona de fato em quase todo o Brasil.

No exemplo sobre o carioquês, há uma descrição de características do ritmo da pronúncia na sintaxe em comparação com outros dialetos/línguas: o mineirês e o baianês. Podemos notar que a descrição do ritmo da pronúncia é um assunto tratado por gramáticos e linguistas. Ao lado disso, os substantivos demora, lerdeza e o advérbio absurdamente, por exemplo, entram na descrição enquanto palavras que trazem uma valorização negativa. Palavras deste tipo não são, atualmente, usadas para uma descrição gramatical ou linguística, mas eram comuns em textos de intelectuais da na virada do século XIX para o século XX.

Pensamos poder dizer que, com um ou outro ajuste, generalização e, claro, tirando o humor, esses três exemplos poderiam fazer parte de descrições gramaticais ou linguísticas ${ }^{19}$. Mas, se, nesses casos, é preciso algum ajuste, no caso do exemplo abaixo, nenhum ajuste parece ser necessário, do ponto de vista formal, para que a descrição seja considerada como uma descrição gramatical ou linguística. Vejamos:

"Exemplos de supressão do pronome oblíquo átono no mineirês:

- Eu formei ano passado."

Aqui é interessante notar que há algo de humor que não está na descrição da forma sintática específica propriamente dita. A descrição dessa forma poderia caber perfeitamente em uma gramática ou em um texto científico. Podemos encontra-la, por

\footnotetext{
${ }^{19}$ Isso nos faz lembrar o diálogo de uma cena do belíssimo filme Trem da Vida, de Radu Mihăileanu, em que Israël ensina alemão sem sotaque ídiche para Mordechaï:

Mordechaï - Freund-chaf-liche Beziehung...

Israël - Freund-schaft-li-che Beziehung!

Mordechaï - Não consigo... Por que é tão difícil? No entanto... se parece tanto com o ídiche! Eu entendo tudo!

Israël - O alemão é uma língua rígida, Mordechaï... precisa e triste. O ídiche é uma paródia do alemão: tem o humor junto. Então, a única coisa que eu peço a você, para que você fale perfeitamente o alemão e perca completamente o sotaque ídiche, é retirar o humor, só isso!

Mordechaï - E os alemães sabem que nós parodiamos a língua deles? Talvez seja esta a causa da guerra, heim?
} 
exemplo, no artigo de R. Freitag (2003), que trata dos pronomes oblíquos átonos reflexivos na fala de Florianópolis, a partir de uma referência a outro artigo, o de Jairo Nunes (1995):

"As mudanças ocorridas no quadro dos pronomes do português parecem ter afetado também os pronomes reflexivos. A tendência para a sua perda foi delineada pelo estudo de Nunes (1995), que enfocou dados da seguinte natureza, os quais ele denomina clíticos anafóricos:

Ele (se) chamava João.

Ontem eu (me) levantei." (p. 63)

O que nos faz rir da descrição do mineirês na Desciclopédia que trata da supressão pronominal não é nem a estrutura da descrição, nem o objeto de descrição e nem o modo como o objeto é descrito, mas os próprios sentidos de mineirês que estão aí funcionando. Há uma memória de sentidos sobre o mineirês em que ele é significado como engraçado. Podemos dizer, a partir disso, que há um saber linguístico sobre o mineirês no qual o humor é constitutivo. Um saber linguístico que não é o da gramática ou da linguística, mas um saber cotidiano, afetado pela gramática e linguística, mas distinto delas. Um saber linguístico cotidiano que se formula nos espaços em que a linguística e a gramática constroem como exteriores a elas ou naqueles espaços em que determinados fatos linguísticos são descritos de maneira lateral, secundária, ou domesticada. Em um ou outro espaço, a gramática e a linguística excluem o que não conseguem reconhecer, seja porque parece impossível ou porque parece interdito descrever ou prescrever. Esse saber linguístico cotidiano se formula, assim, nesse espaço de impossibilidade e interdição - teórica, mas antes histórica, discursiva, ideológica e política - da gramática e da linguística de considerar a existência e ou a legitimidade de determinados fatos linguísticos.

Nesse sentido, perguntamos em que medida temos aí um saber do sujeito brasileiro que fala o seu dialeto/língua, que sabe seu dialeto/língua e que sabe que o sabe, mas de um modo diferente daquele do sujeito gramático, que descreve um saber sobre uma língua que não fala, embora a saiba ou pense que a sabe, ao mesmo tempo em que sabe outro dialeto/língua, mas não pode ou não consegue saber que o sabe. Em que medida há aí outro saber associado, já que o humor da descrição do paulistanês, do mineirês e do carioquês, está indissociavelmente afetado pela descrição séria da língua da gramática. 


\section{Algumas reflexões finais}

Podemos dizer que, no processo de gramatização brasileira do português, a negação da possibilidade de legitimação de uma língua brasileira que definiu parte daquilo que é o específico brasileiro como dialeto, construiu dialetos imaginários. Temos assim, nesse processo, a constituição de uma língua imaginária ao lado de dialetos imaginários, enquanto uma língua que é portuguesa que possui dialetos brasileiros. Ao mesmo tempo, esse processo deu lugar à constituição de uma nãolíngua imaginária, enquanto uma não-língua brasileira, porque língua portuguesa.

A questão do nome da língua foi "resolvida" pela negação da existência da língua brasileira, que a significou como dialeto da língua portuguesa. No entanto, a negação da existência da língua brasileira contribui para a sua existência, permitindo que ela continue existindo e retornando como um saber linguístico, sob diferentes formas.

Algumas dessas formas encontraram lugar nos artigos da Desciclopédia que analisamos, significando o paulistanês, o mineirês e o carioquês como línguas e produzindo outras relações de sentido para os termos língua e dialeto. O saber linguístico que vemos funcionar nesses artigos, de certo modo, "representa alguma verdade", ainda que a Desciclopédia se defina por não representa-la ${ }^{20}$. A paródia constrói um recorte das coisas-a-saber sobre os dialetos/línguas que faz sentido, ainda que não faça sentido para o campo gramatical ou linguístico.

Nesses artigos, a paródia de uma forma de escrita descritiva e/ou normativa, produzida por um sujeito urbano escolarizado, comparece de modo a tratar de características linguísticas de diferentes regiões brasileiras. O humor parodístico está posto aí por uma memória discursiva brasileira, por relações de sentidos construídas historicamente entre a língua portuguesa, a língua brasileira e as noções de língua e dialeto, significando os dialetos/línguas das diferentes regiões do Brasil como engraçados.

Assim, o humor, como constitutivo dessa forma de saber linguístico, tem lugar privilegiado de significação na Desciclopédia. Ela não precisa levar a língua a sério do mesmo modo que a gramática ou a linguística. É pelo humor que o paulistanês, o

\footnotetext{
${ }^{20}$ Ao final do artigo Desciclopédia da Desciclopédia, encontramos o seguinte aviso: "NENHUM artigo da Desciclopédia representa a verdade. TODOS servem apenas como sátira ou humor". Disponível em: http://desciclopedia.org/wiki/Desciclopédia. Acesso: 20 jun. 2016.
} 
mineirês e o carioquês podem significar contraditoriamente como línguas (in)existentes numa relação tensa com a unidade linguística nacional do Estado brasileiro. É pelo humor que elas se constituem, (não) existindo, como outras línguas imaginárias do Brasil.

\section{Bibliografia}

AUROUX, Sylvain. A Revolução Tecnológica da Gramatização. Campinas: Editora da Unicamp, 1992.

A Filosofia da Linguagem. Campinas: Editora da Unicamp, 1998.

DESCICLOPÉDIA. Desciclopédia. Disponível em: http://desciclopedia.org/wiki/Desciclopédia. Acesso: 20 jun. 2016.

Disschionario Aurélo da Língua Carioca. Disponível em: http://desciclopedia.org/wiki/Carioquês. Acesso em: 20 jun. 2016. jun. 2016.

Mineirês. Disponível em: http://desciclopedia.org/wiki/Minerês. Acesso em: 20

Paulistanês. Disponível em: http://desciclopedia.org/wiki/Paulistês. Acesso em: 20 jun. 2016.

DIAS, L. F. Os sentidos do idioma nacional. Campinas: Pontes, 1996.

Formações nominais designativas da língua do Brasil: uma abordagem enunciativa. Letras. Santa Maria, v. 23, n. 46, p. 11-22. jan./jun. 2013. Disponível em: http://periodicos.ufsm.br/letras/article/view/11723. Acesso em: 20 jun. 2016.

Língua e nacionalidade no Brasil na primeira metade do século XX. Polifonia. Cuiabá, MT, v. 22, n. 31, p. 11-31, janeiro-junho, 2015. Disponível em: http://periodicoscientificos.ufmt.br/ojs/index.php/polifonia/article/view/3120/2155.

Acesso em: 20 jun. 2016.

FERREIRA, A. C. F. As coisas-a-saber sobre uma cidade na Wikipédia e na Desciclopédia: Pouso Alegre entre edifícios e buracos. Revista RUA, n. 18, v.2. Campinas: Labeurb/Unicamp, 2012. Disponível em: http://www.labeurb.unicamp.br /rua/pages/home/lerArtigo.rua?pdf=1\&id=133. Acesso em: 18 abr. 2016.

Discursos sobre Cidades na Enciclopédia "Tradicional", na Wikipédia e na Desciclopédia: percursos de sujeitos, saberes e línguas. Em: Cristiane Dias (Org.) Formas de Mobilidade no Espaço E-Urbano: Sentido e Materialidade Digital. Série e-urbano. Vol. 2, 2013, pp. 20-46. Campinas: Labeurb/Nudecri/Unicamp. Disponível em: http://www.labeurb.unicamp.br/livroEurbano/volumeII/arquivos/pdf/eurbanoVol2_ AnaFerreira.pdf. Acesso em: 18 abr. 2016.

O papel e o poder fundador da linguagem na reflexão sobre conhecimento e tecnologia. Entremeios: revista de estudos do discurso, v. 11, jul-dez. Pouso Alegre: PPGCL/Univás, 2015. Disponível em: http://www.entremeios.inf.br/published/300.pdf. Acesso em: 18 abr. 2016.

FREITAG, R. M. K. Uma hipótese de gramaticalização do pronome reflexivo se na fala de Florianópolis. Working Papers em Linguística, v. 7, n. 1. Florianópolis: UFSC, 2003. Disponível em: https://periodicos.ufsc.br/index.php/workingpapers/article/view/ 6167/5722. Acesso em: 12 mai. 2016. 
FORTES, H. P. A língua que falamos. Rio de Janeiro: Edições G.R.D., 1957a.

A questão da língua brasileira. Rio de Janeiro: Edições G.R.D.; 1957b.

GUIMARÃES, E. Língua de Civilização e Línguas de Cultura: a Língua Nacional no Brasil. In: BARROS, D. P. de. Os Discursos do Descobrimento. São Paulo: Fapesp/Edusp, 2000.

. Semântica do Acontecimento. Um Estudo Enunciativo da Designação. Campinas: Pontes, 2002. 2004.

História da Semântica. Sujeito, Sentido e Gramática no Brasil. Campinas: Pontes,

HENGE, G. S. Sujeitos e Saberes: Redes Discursivas em uma Enciclopédia Online. Dissertação de Mestrado. Porto Alegre: Programa de Pós-Graduação em Letras/UFRGS, 2009.

MELO, G. C. (1946) A língua do Brasil. Rio de Janeiro: FGV, 1971.

(1948) Alencar e a "língua brasileira" (seguida de Alencar, cultor e artífice da língua). Departamento de Imprensa Nacional, Conselho Federal de Cultura, 1972, 3. ed.

NASCENTES, A. O linguajar carioca em 1922. Rio de Janeiro: Livraria scientífica brasileira, 1922.

O linguajar carioca. Rio de Janeiro: Organização Simões, 1953, 2. ed.

NUNES, J. H. Para uma História do Discurso Enciclopédico no Brasil. Resumo Expandido apresentado na XXVII ENANPOLL. Niterói: Instituto de Letras/UFF, 2012a. Disponível em: http://www.labeurb.unicamp.br/anpoll/resumos/josehorta.pdf. Acesso em: 17 abr. 2016.

A Enciclopédia Discursiva da Cidade (ENDICI). In: Ana Cláudia Fernandes Ferreira e Ronaldo Teixeira Martins. (Orgs.). Linguagem e Tecnologia. 1ed.Campinas: RG, 2012b, v. 1, p. 159-175.

A cidade enquanto objeto do discurso enciclopédico. Revista RUA (UNICAMP), v. 20, 2014, p. 1-20. Disponível em: http://www.labeurb.unicamp.br/ rua20anos/web/rua2/PDF/Revistas/1/revistaRua_1_5.pdf. Acesso em: 20 jun. 2016.

ORLANDI, E. Língua fluida e língua imaginária. Seminário. IEL/Unicamp, 1985.

Teatro da identidade: a paródia como traço de mistura linguística (italiano/português). Língua e conhecimento linguístico. Para uma história das ideias no Brasil. São Paulo: Cortez, 2002.

Língua brasileira e outras histórias: discurso sobre a língua e ensino no Brasil. Campinas: RG, 2009. 2014.

Ciência da Linguagem e Política: Anotações ao Pé das Letras. Campinas: Pontes,

ORLANDI, E.; GUIMARÃES, E. Formação de um Espaço de Produção Linguística: A Gramática no Brasil In: (Orgs.). História das Ideias Linguísticas: Construção do Saber Metalinguístico e Constituição da Língua Nacional. Campinas/Cáceres: Pontes/Unemat, 2001. 
ORLANDI, E.; SOUZA, T. A língua imaginária e a língua fluida: dois métodos de trabalho com a linguagem. In: Eni Orlandi (Org.) Política Linguística na América Latina. Campinas: Pontes, 1988.

PFEIFFER, C. Bem dizer e retórica: um lugar para o sujeito. Tese de Doutorado. Campinas: IEL/Unicamp, 2000. Disponível em: http://www.bibliotecadigital. unicamp.br/document/?code=vtls000276982. Acesso em: 20 abr. 2016.

PÊCHEUX, M. [1983] O Discurso. Estrutura ou Acontecimento. Campinas: Pontes, 2002, 3ed.

RIBEIRO, J. A língua nacional. São Paulo: Companhia Editora Nacional, 1933.

SANCHES, E. Língua brasileira. São Paulo: Editora Nacional, 1940. (Coleção brasiliana, 179). Disponível em: http://www.brasiliana.com.br/obras/lingua-brasileira. Acesso em: 20 abr. 2016.

SCOTTA, L. Da Enciclopédia Enquanto um Círculo que se Fecha à Wikipédia Enquanto uma Rede que se Abre: um gesto interpretativo. Dissertação de Mestrado. Santa Maria: Programa de Pós-Graduação em Letras/UFSM, 2008.

WIKIPEDIA. Desciclopédia. Disponível em: https://pt.wikipedia.org/wiki/ Desciclopédia. Acesso em: 14 jun. 2016.

Uncyclopedia. Disponível em: https://en.wikipedia.org/wiki/Uncyclopedia. Acesso em: 14 jun. 2016. 


\section{Para citar essa obra:}

FERREIRA, A. C. F. FARIA, J. P. Dialetos/Línguas do Brasil na Desciclopédia. In: RUA [online]. $\mathrm{n}^{\circ}$. 22. Volume 2, p. 593 - 613 - ISSN 1413-2109/2179-9911 Novembro/2016. Consultada no Portal Labeurb - Revista do Laboratório de Estudos Urbanos do Núcleo de Desenvolvimento da Criatividade.

http://www.labeurb.unicamp.br/rua/

Capa: Reprodução. Disponível em:

<http://www.jornalnh.com.br/_conteudo/2015/06/blogs/estilo_de_vida/tecnologia/1811 68-a-desciclopedia-o-facebook-e-a-confusao.html >

Laboratório de Estudos Urbanos - LABEURB

Núcleo de Desenvolvimento da Criatividade - NUDECRI

Universidade Estadual de Campinas - UNICAMP

http://www.labeurb.unicamp.br/

Endereço:

LABEURB - LABORATÓRIO DE ESTUDOS URBANOS

UNICAMP/COCEN / NUDECRI

CAIXA POSTAL 6166

Campinas/SP - Brasil

CEP 13083-892

Fone/ Fax: (19) 3521-7900

Contato: http://www.labeurb.unicamp.br/contato 